Faculdade de Ciências Econômicas UFRGS
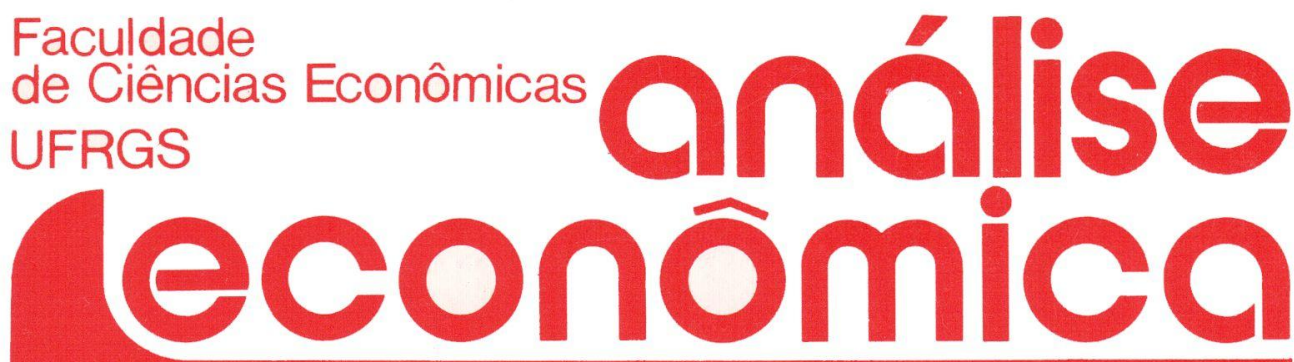

- A DIVIDA EXTERNA: UMA CHANCE DE SOLUÇÃO?

James Kenneth Galbraith

- A ECONOMIA BRASILEIRA VISTA DE FORA

Hartmut Sangmeister

- A QUESTÃO DO INVESTIMENTO Hélio Nogueira da Cruz

- EXCESSO DE CAPACIDADE NA CONCORRÊNCIA MONOPOLISTICA João Rogério Sanson

- MODELOS LINEARES QUADRÁTICOS

Gláucia de Oliva Pretto

- A PEQUENA PROdUÇÃo AGRÍCOLA

Silvana Saionara Gollo

Otto Guilherme Konzen

- ÍNDICE DE PREÇOS AO CONSUMIDOR: UM ESTUDO SOBRE SUA DETERMINAÇÃO NO BRASIL

Neio Lúcio Peres Gualda
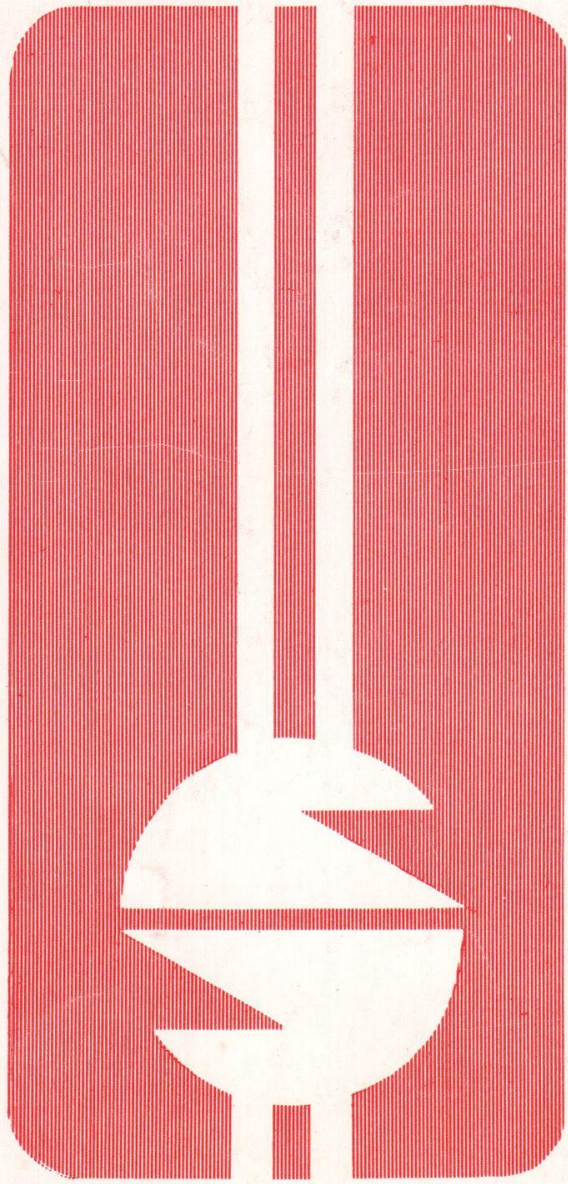
UNIVERSIDADE FEDERAL DO RIO GRANDE DO SUL

Reitor. Prof. Gerhard Jacob

FACULDADE DE CIÊNCIAS ECONÔMICAS

Diretor. Prof. Walter Meucci Nique

CENTRO DE ESTUDOS E PESQUISAS ECONÔMICAS

Diretor: Prof. Reinaldo Ignácio Adams

DEPARTAMENTO DE CIÉNCIAS ECONÔMICAS

Chefe: Prof- Ottlia Beatriz Kroeff Carrion

CURSO DE PÓS-GRADUAÇĀO EM ECONOMIA

Coordenador. Prof. Roberto Camps Moraes

CURSO DE PÓS-GRADUAÇĀO EM ECONOMIA RURAL

Coordenador. Prof. Aray Miguel Feldens

CONSELHO EDITORIAL:

Achyles Barcelos da Costa, Aray Miguel Feldens, Atos Freitas Grawunder, Carlos Augusto Crusius, Ernani Hickmann, Humberto Vendelino Richeter, João Rogério Sanson, Juvir Luiz Mattuella, Maria Imilda da Costa e Silva, Nali de Jesus de Souza, Nuno Renan Lopeś de Figueiredo Pinto, Otllia Beatriz Kroeff Carrion, Otto Guilherme Konzen, Paulo Alexandre Spohr, Pedro Cezar Dutra Fonseca, Reinaldo Ignácio Adams, Roberto Camps Moraes, Valter José Stülp, Yeda Rorato Crusius e Edgar Augusto Lanzer (UFSC).

COMISSÃO EDITORIAL: Atos Freitas Grawunder, Pedro Cezar Dutra Fonseca, Reinaldo Ignácio Adams e Roberto Camps Moraes.

EDITOR: Nali de Jesus de Souza

SECRETARIA: Zélide Bregalda, Francisco Carlos Becco dos Santos, Vanete Ricacheski (revisão de textos), Maria Ivone de Mello (normalização)

FUNDADOR: Prof. Antônio Carlos Rosa

A Revista ANÁLISE ECONÔMICA publica dois números anuais nos meses de março e novembro. O preço da assinatura, para 1989, é de 7,5 BTNs (o núrnero avulso custa 4 BTNs), a ser pago através de cheque nominal em nome da "Faculdade de Ciências Econômicas/ UFRGS". Aceita-se permuta com revistas congêneres. Aceitam-se, também, livros para elaboração de resenhas ou recensões.

Toda correspondência, material para publicação, assinaturas e permutas devern ser dirigidos ao seguinte destinatário:

$$
\begin{gathered}
\text { PROF. NALI DE JESUS DE SOUZA } \\
\text { Revista Análise Econômica } \\
\text { Av. João Pessoa, } 52 \text { - sala } 28 \\
90.040 \text { - PORTO ALEGRE (RS) - BRASIL } \\
\text { Telefone: } 25-5844 \text { ramal } 34
\end{gathered}
$$




\title{
A PEQUENA PRODUÇÃO AGRÍCOLA: SISTEMAS DE PRODUÇÃO E DESEMPENHO
}

\author{
Silvana Saionara Gollo * \\ Otto Guilherme Konzen * *
}

\begin{abstract}
SINOPSE
A pequena produção constitui a grande maioria dảs unidades produtivas rurais de Erechim (RS), municlpio a que este estudo se refere. A presente análise enfoca o desempenho de quatro sistemas e oito subsistemas em relação a produção, emprego, tecnologia e renda familiar.

Constatou-se que as culturas mais importantes do municipio (milho, soja e trigo) respondem pela maior parcela do produto agrlcola, embora a pecuária de leite e de animais de pequeno e médio porte (suínos e aves coloniais) façam parte do conjunto das atividades.

Comparando-se o "tamanho da famflia" e a "disponibilidade da mãode-obra na unidade" com a "área do estabelecimento", observou-se uma relação bastante estreita entre as duas últimas, ou seja, entre a permanência da população na área rural e a oportunidade de emprego nos estabelecimentos agrícolas e pouca relação entre o "tamanho da famflia" e o tamanho do estabelecimento.
\end{abstract}

\section{INTRODUÇÃO}

A pequena produção rural possui no Brasil importância quantitativa no sentido de envolver e constituir o meio de vida para milhares de famílias, ao mesmo tempo que adquire significado qualitativo importante, em virtude do papel que desempenha na produção agrícola e na constituição do preço da força de trabalho (Silva, 1984).

Em 1980, os estabelecimentos de até 50 hectares correspondiam no pals a $82 \%$ do total e retinham $69 \%$ da força do trabalho emprega-

* Mestre em Economia Rural pelo IEPE/UFRGS e professora da Fundação Alto Uruguai para a Pesquisa e o Ensino Superior - FAPES.

* * Economista Rural, PhD, Professor Adjunto da FCE/UFRGS e do Curso de Pós-Graduação em Economia Rural; Pesquisador do IEPE.

ANÁLISE ECONÔMICA ANO 6

№ 10 NOVEMBRO/88 p.87-109 
da no setor, embora ocupando apenas $12,4 \%$ da área global (FIBGE, 1980). A importância deste segmento em relação à produção deriva do fato de contribuirem com mais da metade da produção nacional de alimentos importantes como: amendoim, arroz, batata-inglesa, cebola, feijāo, mandioca, milho e uva (Wright \& Rego, 1983).

Graziano da Silva assinalou como caracteristicas da pequena produção: a) a mão-de-obra familiar, de modo que a família constitui a unidade de produção; b) a família enquanto proprietária dos seus instrumentos de trabalho ou parte deles; c) posse da terra, não sendo essencial a propriedade da mesma; d) a existência de fatores (terra, força de trabalho, meios de trabalho) que permitam alguma produção de excedentes destinados à subsistência. Alguma produção comercial é necessária à sobrevivência dessa forma de produção (Silva, 1984).

Outras características da pequena produção são: atividades diversificadas de culturas, geralmente consorciadas; tecnologia tradicional ou incorporação apenas parcial de melhorias tecnológicas; escassez de terra, limitativa à adoção de técnicas que exijam escala de produção mínima; acesso restrito a alguns meios de produção; baixa produtividade do trabalho e, com isso, valor de renda familiar baixo (Konzen e Richter, 1982; Silva, 1984; Kageyana e Silva, 1986; Konzen, 1986).

Em resumo, a pequena produção pode ser caracterizada como aquela que apresenta pouca disponibilidade de terra, emprega mãode-obra familiar, pratica a policultura de forma isolada ou em consorciação, registra insuficiência de capital, utiliza baixo nível tecnológico, obtém baixa produtividade do trabalho e, em conseqüência, gera baixo nivel de renda.

No Rio Grande do Sul, a pequena produção, enquanto representada pelos estabelecimentos de até 50 hectares de área, correspondia, em 1980 , a $86 \%$ das unidades produtivas e ocupava $80,2 \%$ da mão-deobra empregada no setor; detinha $25 \%$ da área estadual. Este conjunto de unidades produziu naquele ano, $99 \%$ da batata-inglesa, $98 \%$ da cana-de-açúcar, $89 \%$ do amendoim, $80 \%$ do milho, $84 \%$ do feijāo, $86 \%$ da mandioca, $80 \%$ das laranjas, $42 \%$ da soja, $29 \%$ do trigo e $9 \%$ do arroz, além de $80 \%$ dos ovos, $88 \%$ das aves, $77 \%$ do leite e $84 \%$ dos suínos (FIBGE, 1983).

Destaca-se, portanto, a pequena unidade de produção pela densidade de emprego, alto valor de produção por unidade de área, mas baixa renda por pessoa ocupada, como indica a tabela que segue. 
TABELA 1 - PESSOAS OCUPADAS POR ESTABELECIMENTO E POR HECTARE, VALOR DA PRODUÇ̃̃ POR PESSOA OCUPADA E POR HECTARE, POR GRUPOS DE ÁREA DO RIO GRANDE DO SUL - 1980.

\begin{tabular}{lcccc}
\hline $\begin{array}{l}\text { Grupos de } \\
\text { área (Ha) }\end{array}$ & $\begin{array}{c}\text { Pessoas Ocupadas } \\
\text { por } \\
\text { estabelec. }\end{array}$ & por Ha & $\begin{array}{c}\text { Valor Bnto de Produçă }{ }^{*} \\
\text { por pessoa } \\
\text { ocupada } \\
\text { Cz } \$ \text { P/ano }\end{array}$ & por Ha \\
\hline $0-10$ & 2,89 & 0,59 & 52,08 & 30,67 \\
$10-20$ & 3,55 & 0,26 & 76,95 & 19,78 \\
$20-50$ & 4,04 & 0,14 & 102,99 & 14,21 \\
$50-100$ & 4,24 & 0,06 & 153,99 & 9,68 \\
$100-200$ & 4,39 & 0,03 & 256,83 & 8,21 \\
$200-500$ & 5,52 & 0,02 & 403,17 & 7,19 \\
$500-$ mais & 10,28 & 0,01 & 579,63 & 4,76 \\
Sern declaração & 1,10 & - & - & - \\
\hline TOTAL & 3,68 & 0,07 & 126,24 & 9,17 \\
\hline
\end{tabular}

FONTE: GOLLO, 1987, tabelas 1 e 2.

*Elaborado a partir da fonte.

Enquanto no estabelecimento de até 10 hectares emprega-se 0,59 pessoa por hectare, nos estabelecimentos de área superior a 500 hectares, emprega-se 0,01 pessoa, ou seja, uma pessoa a cada 121 hectares. A relação inversa entre emprego por hectare e área total é fato amplamente conhecido e constatado ao longo de todos os estratos de área adotados na tabela.

Embora algumas caracteristicas sejam comuns às pequenas unidades produtivas, existem diferenças acentuadas dentro deste segmento que originam um processo de diferenciação social progressiva. O elemento básico está no grau de limitação restritivo dos recursos físicos e capacidade gerencial que influenciam o procesśo de tecnificação e capitalização, conduzindo algumas unidades à formação de pequenas empresas familiares; outras, à proletarização e marginalização da atividade produtiva (Kageyama e Silva, 1986; Konzen, 1986; Konzen e Richter, 1982). 
Assim, um dos problemas centrais está no grau de restrição que os recursos disponiveis, principalmente a potencialidade da terra, representa em termos de opçōes de modernização e capitalização da produção e do nível de renda atingível pela unidade familiar.

\subsection{Problema}

No Rio Grande do Sul, o desenvolvimento agrícola teve suas bases assentadas, durante a primeira metade da década de 70 , na elevação da demanda e nos preços internacionais da soja e por uma política de crédito, fomento e apoio técnico, que permitiu a expansão desta cultura. O processo de incentivo ao setor agrícola propiciou um reflexo positivo, também, nos setores agroindustrial, agrocomercial e de serviços.

No final da primeira metade da década de 70 , o primeiro choque do petróleo resultou num aumento acentuado dos preços das matériasprimas básicas que serviram de insumos à produção de fertilizantes, defensivos agrícolas e combustiveis, cuja conseqüência foi um aumento contínuo dos custos de produção. Até 1979, quando sobreveio o segundo choque do petróleo, o setor agricola pôde manter-se com ganhos relativos devido à política de preços e de crédito ainda favoráveís. No entanto, a partir de então, as restrições de crédito atingiram negativamente o setor agrícola que se tinha voltado a uma monocultura custeada com recursos de terceiros a juros subsidiados.

No caso do município de Erexim, no início da década de 70, com a difusão dos sistemas de sucessão trigo/soja ou consorciação milho $x$ soja e com a disponibilidade de crédito, a pequena produção agrícola aumentou a área destas culturas, o uso de equipamentos mecânicos e de adubos químicos em detrimento da produção de subsistência e do sistema tradicional de rotação de culturas com pastagens. A má qualidade dos solos da região e as restrições posteriores de crédito impossibilitaram a pequena produção de manter o nivel tecnológico, exigido por estas atividades. Com o progressivo desgaste do solo, devido à intensificação da produção (duas safras anuais), a produtividade do trigo vem caindo rapidamente e a produtividade da soja e do milho apresentam acréscimos muito pequenos. $O$ nível de renda dos pequenos produtores, por influência destes fatores, é baixo, obrigando-os a retornar à tecnologia tradicional. A força de trabalho humano, ocupada nas propriedades, é familiar e nos últimos anos registrou-se um fluxo migratório da população rural para os centros urbanos do próprio municipio, 
para a Oeste Catarinense, Sudoeste do Paraná, Sul do Mato Grosso do Sul e Amazonas (PIRAN, 1982).

Em Erexim, as pequenas unidades predominam com $88,7 \%$ dos estabelecimentos abaixo de 50 hectares. Além disso, a baixa fertilidade do solo e declividades acentuadas restringern a potencialidade da terra.

Face ao atual incentivo de redirecionar a agricultura, particularmente as pequenas unidades, à policultura com vistas ao abastecimento interno, justifica-se a busca de opções viáveis para as pequenas unidades familiares, como as de Erexim. Por isso, o problema central da pesquisa é encontrar um plano diversificado de atividades, que utilize eficazmente os recursos disponiveis com aurnentos da renda do pequeno produtor.

\subsection{Objetivos}

Como objetivo geral, a pesquisa buscou identificar, a partir do diagnóstico da situação existente, planos diversificados de atividades agrícolas capazes de aumentar o emprego e a renda dos pequenos produtores rurais de Erexim, sem descaracterizar os sistemas produtivos.

Os objetivos deste trabalho são:

1) diagnosticar na pequena produção rural de Erexim, por sistemas de tamanho, os recursos disponiveis, as principais atividades praticadas, a produção obtida, a tecnologia utilizada, o nível de renda e o emprego;

2) identificar novos sistemas, dentro dos anteriores, que caracterizem combinaçōes diferenciadas de atividades e analisá-los em termos de uso dos recursos e dos resultados que alcançaram.

\section{2. ÁREA DE ESTUdO E ABORDAGEM DA ANÁLISE}

A área pesquisada é o município de Erexim, na regiāo do Alto Uruguai do Rio Grande do Sul e integrante da Microrregião "colonial de Erexim".

A Colônia de Erexim foi fundada em 1908, sendo estabelecidos pequenos lotes de aproximadamente 25 hectares e, posteriormente, também de 12,5 hectares, com o propósito de estimular uma policultu- 
ra alimentar destinada ao mercado urbano interno. Em 30 de abril de 1918, a Colônia emancipou-se e foi criado o municipio de Erexim com 38.000 habitantes (Cassol, 1979). Em 1980, a população do município tinha ultrapassado os 60.000 habitantes, com $78,9 \%$ na área urbana, contra $21,1 \%$ na área rural e uma densidade média de 74,8 habitantes por quilômetro quadrado (FIBGE, 1980).

A estrutura fundiária atual está bastante alterada em relação à ocupação original, com uma compartimentalização dos pequenos produtores enquanto os grandes aumentaram ainda mais suas áreas, aguçando as diferenças da época de sua implantação (Piran, 1982).

As unidades entre zero e 50 hectares são $88,7 \%$ do total em 1980; abaixo de 10 hectares estão $20 \%$ das unidades; entre 10 e 50 hectares estão mais de dois terços $(68,7 \%)$; entre 50 e 100 hectares são $10,1 \%$, restando $1,2 \%$ dos estabelecimentos com área superior a 100 hectares (Gollo, 1987).

Pela classificação do Censo Agropecuário, $56 \%$ do total dos 2.536 estabelecimentos dedicam-se à agricultura, $33 \%$ à pecuária $e$ $6 \%$ à agropecuária; os restantes $5 \%$ à hortifruticultura, silvicultura, avicultura e atividades extrativas.

A soja é a atividade economicamente mais importante, com $53,4 \%$ da área cultivada e propiciando $53,7 \%$ do valor bruto da produção; é seguida do milho, com 33,9\% da área e 30,4\% do valor da produção; é seguida do milho, com 33,9\% da área e 30,4\% do valor da produção. Outras atividades importantes são: trigo, feijão, arroz, mandioca, erva-mate, uva, abóbora, batata-inglesa, batata-doce, cana-deaçúcar e amendoim.

Além da produção de culturas, têm destaque a suinocultura, bovinocultura leiteira e aves colonias. Conjuntos diversificados de culturas, juntamente com produções pecuárias, integram os sistemas municipais na região.

As informações primárias para o estudo foram obtidas por uma pesquisa de campo, através de amostra aleatória, estratificada, tendo como variável-critério a área do estabelecimento rural.

$\mathrm{Na}$ pesquisa de campo, que também serviu de base para outros trabalhos, foram investigados todos os tamanhos de estabelecimentos, numa amostra total de 103 unidades de observação.

Para os fins deste trabalho, a amostragem compreende somente os estabelecimentos de até 5 hectares ( 83 observações), que estão estratificados em quatro grupos de tamanho: zero a 12,5 hectares (15 
observações); 12,5 a 25,0 hectares (38 observaçōes); 25,0 a 37,5 hectares (14 observações); e, 37,5 a 50,0 hectares (16 observaçōes).

A coleta de dados foi realizada com a colaboração de professores e equipe de pesquisa do IEPE, direção, professores, alunos e funcionários da FAPES, Prefeitura Municipal de Erexim, COTREL, EMATER e Sindicato dos Trabalhadores Rurais de Erexim.

\subsection{Modelo Operacional}

A primeira origem de diversificação entre pequenas unidades, consideradas no estudo, é o tamanho da área de exploraçāo. A partir de estratos de tamanho, estabeleceu-se um protótipo de propriedade média do grupo, em termos de áreas (total e diferentes usos), outras formas de capital físico (máquinas, construçōes, rebanhos), māo-deobra e atividades. Obtiveram-se, com isto, quatro sistemas de produção, cuja característica diferenciadora de base é a área da unidade produtiva.

Diferenças observadas dentro de cada estrato levou a uma partição adicional em função das atividades praticadas. Para cada grupo inicial, estabeleceram-se dois subsistemas. Dividiram-se as somas observadas das áreas, recursos e dimensões das atividades pelas unidades que praticavam efetivamente as atividades, não pelo número de observação no subgrupo de observaçōes.

As atividades identificadas pela pesquisa da região e que foram incluídas na análise pela sua importância são:

a) atividades vegetais: arroz, batata-inglesa, feijão, mandioca, milho, soja e trigo;

b) atividades animais: bovinos de leite, suínos e aves coloniais.

A disponibilidade de mão-de-obra foi igualada à existente na família e foi dividida em comum (utilizada em tarefas gerais e de processos de tração animal) e em especializada (ocupada com tarefas de tração mecânica).

A quantificação da mão-de-obra é feita em equivalentes-homem $(E H)$ e consideráram-se, em média, 23 dias de atividađes agrícolas por mês, com 9 horas diárias de trabalho (Gollo 1987, p. 41-3).

A disponibilidade de tração animal foi estabelecida pelas médias de juntas de boi, constatadas nos sistemas e subsistemas; a tração mecânica também baseou-se no levantamento, mas os tratores de di- 
ferentes potências foram uniformizados em equivalentes-trator, tendo como unidade um trator médio (de 50- a $100 \mathrm{HP}$ ).

Os preços considerados para produtos e insumos foram os divulgados pela EMATER/RS para o periodo de março de 1985 a fevereiro de 1986, foram todos atualizados para este mês através do IGP (disponibilidade interna), publicado pela FGV.

\section{DESCRIÇÃO DA SITUAÇÃO ATUAL POR SISTEMAS}

Nesta etapa, estuda-se a situação existente em relação aos quatro sistemas, por estratos de tamanho especificados, que compóem a pequena produção rural do município de Erexim. Os aspectos estudados são: o uso da terra; as atividades principais e o destino da produção agrícola; o emprego da força de trabalho familiar e a margem bruta da renda auferida.

\subsection{Uso da Terra em Cada Sistema}

A pequena propriedade de Erexim explora produtivamente dois terços da área total que administra; um terço, aproximadamente, está ocupado com a sede, matas, capoeiras ou são áreas inaproveitáveis, conforme evidencia a tabela 2.

\section{TABELA 2 - USO DA TERRA POR SISTEMA, EREXIM, RS 1984/1985}

Áreas de Amostra Áreas relativas dos Sistemas

\begin{tabular}{lrrrrrr} 
& $\begin{array}{c}\text { Média } \\
\text { VARIÁVEIS }\end{array}$ & $\begin{array}{c}\text { Relativa } \\
(\%)\end{array}$ & \multicolumn{1}{c}{$\mathrm{S}_{1}$} & \multicolumn{1}{c}{$\mathrm{S}_{2}$} & \multicolumn{1}{c}{$\mathrm{S}_{3}$} & $\mathrm{~S}_{4}$ \\
\hline Cult. Anuais & 13,2 & 49,9 & 52,5 & 51,2 & 52,7 & 46,9 \\
Pastagens & 3,8 & 14,2 & 16,3 & 14,2 & 15,7 & 12,7 \\
Forrageiras & 0,1 & 0,5 & 1,4 & 0,7 & 0,4 & 0,2 \\
Cult. Permanentes & 0,5 & 1,9 & 5,0 & 2,9 & 1,9 & 1,0 \\
Capoeiras ou em descanso & 4,1 & 15,6 & 9,5 & 13,1 & 14,6 & 18,7 \\
Matas e reflorestamentos & 3,1 & 1,7 & 9,8 & 11,9 & 8,9 & 13,9 \\
Outros (sede, inaproveitáveis) & 1,6 & 6,2 & 5,5 & 6,0 & 5,9 & 6,6 \\
\hline SOMA & 26,4 & 100,0 & 100,0 & 100,0 & 100,0 & 100,0 \\
\hline Tamanho Médio (HA) & 26,4 & - & 8,2 & 20,4 & 32,2 & 44,9 \\
\hline
\end{tabular}

Fonte: Dados da Pesquisa. 
As culturas anuais ocupam a maior parte da área explorada economicamente, chegando a $50 \%$ da área total; pastagens ocupam aproximadamente $15 \%$; outros $15 \%$ estão em descanso, ocupados com capoeiras e pouco mais de $10 \%$ são mantidos em florestas nativas ou plantadas; o restante, entre $5 \%$ e $12 \%$, constitue a área da sede, com outras culturas permanentes e as fraçōes de terra não utilizáveis.

Constata-se bastante semelhança nos três primeiros sistemas, no tocante as áreas relativas de culturas anuais, pastagens, mato e reflorestamento; o quarto sistema (o estrato de maior área) cultiva e mantém áreas relativas pouco menores, com áreas de pastagens, mantendo uma diferença para mais nas áreas em descanso e florestas. Estas se relacionam, de modo geral, no município, positivamente, com o tamanho dos estabelecimentos; a medida que se passa do sistema de menores áreas as de maiores, aumenta, em média, o percentual da área mantida com florestas.

\subsection{Atividades}

Erexim é um município com predominância da agricultura sobre atividades de pecuária. A suinocultura e a produção de leite têm expressão comercial; outros bovinos são mantidos como fonte de tração. A criação de aves está basicamente em função do consumo familiar, sendo raramente desenvolvida para fins de geração de renda monetária na forma colonial de produção. Recentemente, está aumentando a produção comercial de aves e suínos pela integração com a indústria.

As atividades principais desenvolvidas pela pequena produção de Erexim são as culturas de milho e soja, em plantios isolados ou em consorciação, e a sucessão trigo-soja. $O$ pequeno produtor também se dedica à produção de subsistência como feijão, arroz, mandioca, batata-inglesa, frutas, parte do leite e dos suínos e aves coloniais. As atividades de lavouras estão indicadas na tabela seguinte.

O milho ocupa uma média de $39,2 \%$ e a soja $37,9 \%$ sobre a área das lavouras de verão. Entre os sistemas, observa-se um incremento de importância, em termos de área relativa, do plantio isolado dessas culturas, à medida que aumenta o tamanho dos sistemas no plantio em consórcio, a combinação milho $x$ soja diminui de importância na passagem de estabelecimentos menores para maiores; de $35,1 \%$ da área de lavouras no primeiro sistema, reduz-se para $4,9 \%$ no último de 
maior área. Isto, embora os dados não o mostrem explicitamente, decorre da mecanização mais freqüente nas unidades maiores.

O trigo constitui a terceira cultura mais importante em área cultivada nos três primeiros sistemas; no quarto sistema, essa cultura tem destaque menor, ocupando, em média, pouco menos de $7 \%$ da área cultivada.

TABELA 3 - ÁREAS DAS ATIVIDADES PRINCIPAIS DE LAVOURAS, EREXIM, RS - 1984/85.

\begin{tabular}{|c|c|c|c|c|c|c|}
\hline \multirow[b]{2}{*}{$\begin{array}{l}\text { Atividades de } \\
\text { Lavouras }\end{array}$} & \multicolumn{2}{|c|}{ Áreas de Amostra } & \multicolumn{4}{|c|}{ Áreas Relativa dos Sistemas } \\
\hline & Média & $\begin{array}{c}\text { Relativa } \\
\%\end{array}$ & $s_{1}$ & $S_{2}$ & $s_{3}$ & $S_{4}$ \\
\hline Milho & 5,17 & 39,2 & 35,5 & 36,0 & 39,1 & 41,7 \\
\hline Soja & 5,00 & 37,9 & 16,1 & 27,6 & 35,8 & 49,3 \\
\hline Milho $\times$ Soja & 2,00 & 15,2 & 35,1 & 23,2 & 18,5 & 4,9 \\
\hline Trigo * & 1,40 & $(10,6)$ & $(11,7)$ & $(14,2)$ & $(12,9)$ & $(6,8)$ \\
\hline Feijão & 0,52 & 3,9 & 9,3 & 5,3 & 3,8 & 2,3 \\
\hline Mandioca & 0,19 & 1,5 & 2,1 & 2,4 & 1,5 & 0,7 \\
\hline Arroz & 0,26 & 2,0 & 1,6 & 4,8 & 1,3 & 1,1 \\
\hline Batata-Inglesa & 0,04 & 0,3 & 0,5 & 0,6 & - & - \\
\hline SOMA & 14,58 & 100,0 & 100,0 & 100,0 & 100,0 & 100,0 \\
\hline Área Média de Lavouras $(\mathrm{Ha})$ & 13,18 & - & 4,28 & 10,46 & 16,96 & 21,04 \\
\hline
\end{tabular}

FONTE: Dados de Pesquisa

* Área não incluida na média nem na soma das relativas por ser de inverno, em sucessão à soja.

As atividades de gado leiteiro, produção de suínos e aves coloniais são partes integrantes da pequena produção em Erexim, e são praticadas em tơdos os estabelecimentos. A quantidade de animais, constatada na pesquisa, é indicada na tabela a seguir.

Embora leite, ovos e aves destinem-se prioritariamente à alimentação da família, os excedentes desses produtos são comercializados. No caso dos suínos, a produção destina-se ao duplo destino de con- 
sumo pela família e comercialização, mas com a diferença de que a atividade, em muitos casos, é essencialmente mercantil e apenas complementarmente de destino doméstico.

TABELA 4 - PRODUÇÃO PECUÁRIA NO MUNICÍPIO DE EREXIM, RS 1984/85.

\begin{tabular}{lc|rrrr} 
& Média da & \multicolumn{4}{|c}{ Sistemas } \\
\cline { 3 - 6 } & Amostra & \multicolumn{1}{c|}{$\mathrm{S}_{1}$} & $\mathrm{~S}_{2}$ & $\mathrm{~S}_{3}$ & $\mathrm{~S}_{4}$ \\
\hline Bovinos & & & & & \\
Vacas Leiteiras & 2,6 & 2,0 & 2,6 & 2,3 & 3,4 \\
Outros & 3,9 & 2,7 & 4,4 & 4,2 & 3,8 \\
Suínos & & & & & \\
Matrizes & 2,8 & 1,6 & 2,9 & 3,0 & 3,3 \\
Outros & 17,6 & 11,2 & 13,4 & 9,9 & 40,1 \\
Aves & 81,6 & 58,0 & 105,0 & 66,0 & 62,0 \\
\hline
\end{tabular}

FONTE: Dados de Pesquisa.

No cômputo da contribuição para a renda familiar, as margens das atividades pecuárias foram estimadas, com base nas existências de animais e não calculadas diretamente, como será detalhado mais adiante.

\subsection{Destino da Produção Agricola}

Em Erexim, reproduz-se o padrão típico da pequena produção familiar em que a diversificação de atividades assegura a subsistência das pessoas residentes na propriedade, mas inclui atividades cujo objetivo é geração de renda monetária. Como já assinalado, suínos e excedentes de leite e ovos constituem, com freqüência, fontes de renda monetária.

Entre as atividades de lavoura, a soja é tipicamente cultura comercial; outras culturas são destinadas em parte a comercialização como trigo 84,2\%; feijão 72,4\% e milho 19,0\%. (GOLLO, 1987 ). 


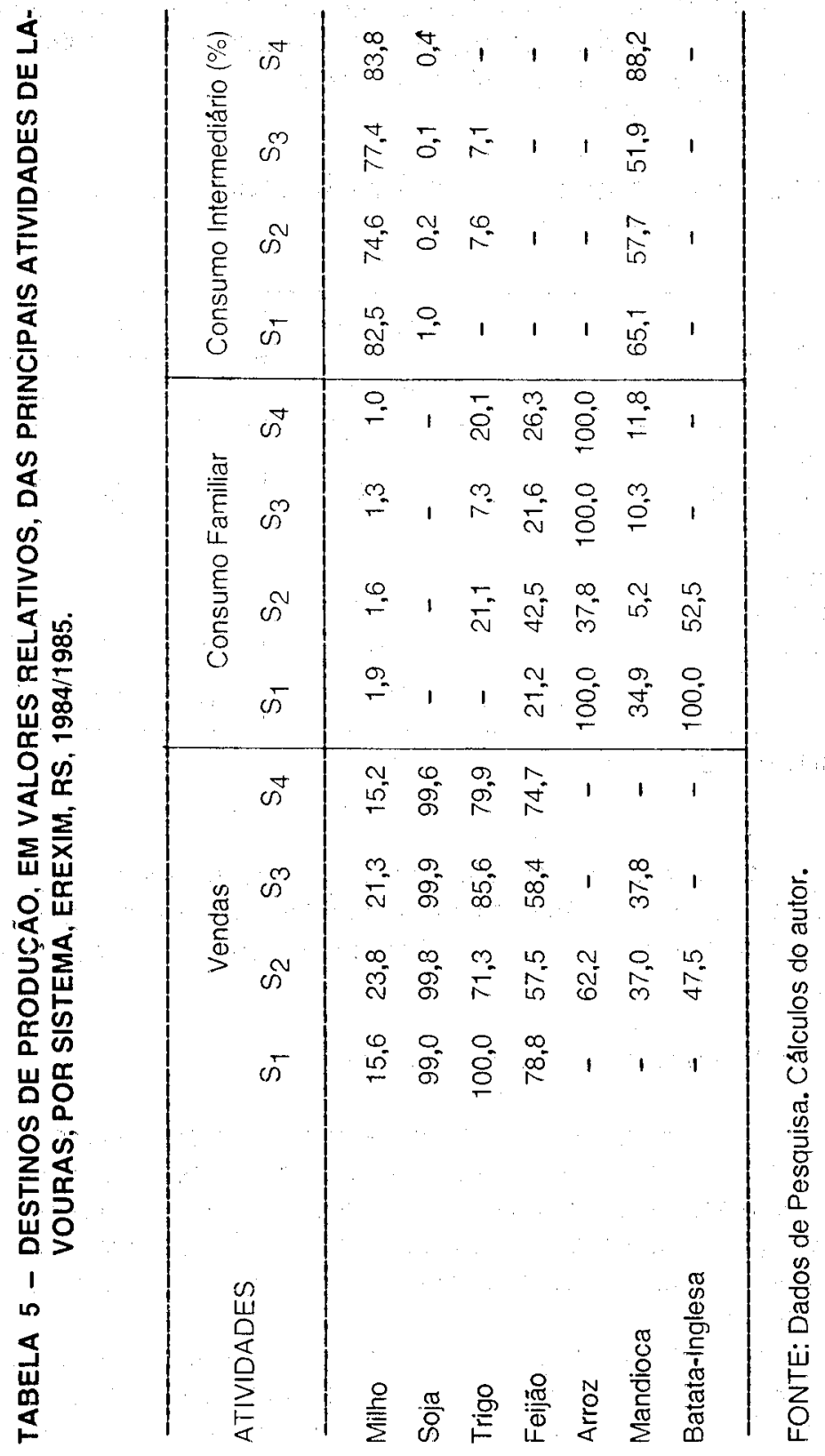


Com exceção da soja, essas culturas também se destinam, em parte, ao consumo familiar. Ainda se destinam à subsistência do agricultor o arroz, a batata-inglesa e parte da mandioca. *

A maior parte da produção de milho e mandioca e uma pequena fração de soja são utilizadas como trato de animais.

\section{TABELA 6 - PRODUÇÃO E PRODUTIVIDADE DAS PRINCIPAIS CUL- TURAS, POR SISTEMA, EREXIM, RS - 1984/1985.}

\begin{tabular}{lcrrr|rrrr}
\hline \multirow{2}{*}{ Atividades } & \multicolumn{4}{c|}{ Produção $(\mathrm{Kg})$} & \multicolumn{4}{|c}{ Produtividade (Kg/Ha) } \\
& $\mathrm{S}_{1}$ & \multicolumn{1}{c}{$\mathrm{S}_{2}$} & \multicolumn{1}{c}{$\mathrm{S}_{3}$} & \multicolumn{1}{c}{$\mathrm{S}_{4}$} & $\mathrm{~S}_{1}$ & $\mathrm{~S}_{2}$ & \multicolumn{1}{c}{$\mathrm{S}_{3}$} & $\mathrm{~S}_{4}$ \\
\hline Milho * & 5.490 & 11.626 & 16.468 & 17.836 & 2533 & 2361 & 2275 & 2154 \\
Soja & 3.983 & 7.900 & 13.226 & 16.350 & 2074 & 1910 & 1791 & 1604 \\
Trigo & 383 & 1.250 & 1.691 & 1.176 & 765 & 781 & 776 & 859 \\
Feijão & 226 & 332 & 459 & 431 & 603 & 621 & 817 & 920 \\
Arroz & 78 & 476 & 194 & 197 & 1114 & 1106 & 1174 & 1169 \\
Mandioca & 375 & 1.888 & 1.786 & 1.020 & 8333 & 8340 & 9144 & 9333 \\
Batata-Inglesa & 102 & 305 & - & - & 5750 & 5083 & - & - \\
\hline
\end{tabular}

FONTE: Dados de Pesquisa

* As produtividades são as de plantios isolados.

Os dados indicam que a produtividade média do milho e da soja, em plantios isolados, diminui entre os sistemas, à medida que aumenta o tamanho dos mesmos; os niveis de adubação para essas culturas também variam no mesmo sentido (GOLLO, 1987, tabela 27).

A produtividade média, observada para o feijāo, varia no sentido do tamanho médio dos sistemas, embora as áreas plantadas não se diferenciem no mesmo sentido.

Para outras culturas, como trigo e arroz, os dados não assinalam associação entre tamanho da unidade de produção e a produtividade.

\section{DESCRIÇÃO DOS SUBSISTEMAS}

As atividades desenvolvidas por produtores dentro dos sistemas

\footnotetext{
"Além das atividades assinaladas na tabela 6 , produzem-se no municlpio outros produtos alimentares, que constituem parte do consumo farniliar.
} 
estabelecidos não são uniformes, encontrando-se diferentes conbinações de atividades dentro de cada estrato. Por isso, estabeleceram-se dois subgrupos de unidades em cada sistema. Estes subgrupos constituem os subsistemas e são considerados como unidades típicas em cada sistema por estrato de área. Distinguem-se, assim, oito subsistemas típicos dentro da pequena produção do município.

\subsection{Composição de Atividades nos Subsistemas}

No caso dos sistemas, os cálculos das médias foram obtidos pelo somatório das áreas ou unidades de cada atividade, dividida pelo número total de observações do respectivo grupo. No caso dos subsistemas, dividiu-se o somatório das observações pelo número dos produtores que efetivamente praticam as atividades computadas, estabelecendo-se uma relação mais exata entre atividade e recurso.

TABELA 7 - ÁREAS DAS ATIVIDADES DE LAVOURAS POR SUBSISTEMA (SB), EREXIM, RS - 1984/1985.

\begin{tabular}{l|cccccccc}
\hline \multirow{2}{*}{ Atividades } & \multicolumn{10}{|c}{ Áreas (Ha) } \\
\cline { 2 - 9 } & $S_{1}$ & $S_{2}$ & $S_{3}$ & $S_{4}$ & $S_{5}$ & $s_{6}$ & $S_{7}$ & $S_{8}$ \\
\hline Milho & 2,33 & - & - & 7,84 & 7,50 & 9,13 & 7,25 & 10,50 \\
Soja & - & - & - & 4,50 & 5,00 & 8,83 & 19,75 & 16,60 \\
Milho x Soja & - & 5,50 & 6,20 & - & 7,00 & - & 1,00 & - \\
Trigo & - & 3,00 & 1,65 & 4,22 & 2,50 & 5,83 & 4,50 & 5,00 \\
Feijão & 0,37 & 0,50 & 0,67 & 0,67 & 0,30 & 1,35 & 1,06 & 0,50 \\
Mandioca & 1,00 & 0,25 & 0,60 & 0,11 & 0,30 & 0,55 & 0,40 & 0,75 \\
Arroz & 0,45 & - & 0,25 & 0,68 & - & 0,54 & 0,25 & 0,55 \\
Batata-Inglesa & 0,02 & - & 0,13 & 0,23 & - & - & - & - \\
\hline
\end{tabular}

Soma das

Lavouras

$\begin{array}{llllllll}4,17 & 6,25 & 7,85 & 14,03 & 20,10 & 20,40 & 29,71 & 28,90\end{array}$

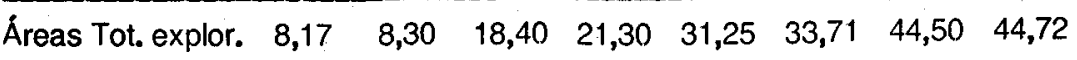

FONTE: Dados de Pesquisa.

* A soma não inclui a área de trigo por ser de duplo plantio, em sucessão a soja ou milho no mesmo ano agricola. 
Pelas informações da tabela, constata-se que milho (isolado ou em consórcio corn soja), feijão e mandioca são cultivados em cada um dos subsistemas; soja, trigo e arroz em quase todos, e batata-inglesa, apenas em alguns dos menores subsistemas.

Milho e soja são plantados de forma consorciada, com mais freqüência, nos subsistemas de menores áreas, e de forma isolada nos de áreas maiores, o que é consistente com as condições de viabilidade de mecanização. Em todos os subsistemas, milho e soja são as atividades principais, com relação a área de plantio.

Nos primeiros seis subsistemas, o milho é a cultura predominante em termos de área e nos outros dois, os de área acima de 37,5 hectares, a soja sobrepōe-se às demais culturas, inclusive ao milho.

$\mathrm{O}$ trigo que pode ser considerado um complemento à soja utilizando a mesma área e os mesmos equipamentos, sempre é cultivado em áreas menores do que esse e aparece como relativamente menos importante nos subsisternas de maiores áreas.

Feijão, mandioca, arroz e batata-inglesa não têm uma relação definida com a área total do subsistema, o que indica sua orientação apenas secundária para o mercado e mais direta às necessidades de consumo pela família e, no caso da mandioca, como complemento à alimentação dos animais.

As produções de animais não são fatores de distinção sistemática entre subsistemas, como se percebe da tabela seguinte.

TABELA 8 - EXISTÊNCIAS DE ANIMAIS E AVES, POR SUBSISTEMA, EREXIM, RS - 1984/1985.

\begin{tabular}{llllllllll}
\hline $\begin{array}{l}\text { Ativi- Unidade } \\
\text { dade }\end{array}$ & $\mathrm{SB}_{1}$ & $\mathrm{SB}_{2}$ & $\mathrm{SB}_{3}$ & $\mathrm{SB}_{4}$ & $\mathrm{SB}_{5}$ & $\mathrm{SB}_{6}$ & $\mathrm{SB}_{7}$ & $\mathrm{SB}_{8}$ \\
\hline $\begin{array}{l}\text { Aves Cabeças } \\
\text { Bovino }\end{array}$ & 5,0 & 5,0 & 10,8 & 12,1 & 7,5 & $5,7^{\prime}$ & 7,0 & 5,0 \\
$\begin{array}{l}\text { de Leite Cabeças } \\
\text { Suinos Matrizes }\end{array}$ & 5,7 & 4,0 & 1,7 & 2,4 & 3,3 & 4,0 & 2,0 & 3,0 & 3,5 \\
\hline
\end{tabular}

FONTE: Dados da Pesquisa. 
As aves de produção colonial, os bovinos de leite e os suínos são atividades praticadas em todos os subsistemas, mas não apresentam variações significativas no nivel de exploração entre os mesmos. A avicultura é praticada em maior nível nos subsistemas três e quatro (á reas de 12,5 a 25 hectares), e a suinocultura parece relacionar-se com o tamanho das unidades de produção.

Os subsistemas, comparados aos pares, mostram as diferenças que os caracterizam como desdobramentos dos sistemas iniciais. Com relação ao primeiro par (SB1 e SB2), a diferença básica está na concentração de um subgrupo como produtor de milho $x$ soja e trigo, como lavouras principais, ao passo que o outro subsistema não planta soja ou trigo, atendo-se totalmente às culturas de consumo prioritário dentro da unidade de produção (milho, feijão, mandioca, arroz e batata-inglesa).

O principal elemento diferenciador dos subsistemas três e quatro está em que o primeiro produz milho e soja em consorciação, acompanhados de uma área pequena de trigo, ao passo que o segundo cultiva milho e soja de forma separada e em áreas acentuadamente maiores; além disso, planta trigo em áreas quase iguais às da soja; os dois subsistemas são semelhantes em cultivar pequenas áreas das culturas de subsistência e nas atividades pecuárias.

A distinção entre os subsistemas do teiceiro par é semelhante à do anterior. O primeiro subgrupo planta grande parte do milho e soja em consórcio, e cultiva relativamente pouco trigo; o segundo não planta ou planta pouco trigo.

A diferença entre os subsistemas de maiores áreas (SB7 e SB8) está na predominância maior da soja sobre o milho em um subgrupo em relação ao outro.

\subsection{Disponibilidade e Ocupação da Mão-de-Obra Familiar nos Subsistemas}

A pesquisa indicou que é preciso fazer uma distinção entre a família rural e a força de trabalho familiar na pequena produção de Erexim. Em família rural, estão incluidas todas as pessoas da família, casadas'ou não, residentes ou não na unidade de produção. Em força de trabalho familiar, computou-se apenas a mão-de-obra disponivel para as atividades produtivas. Ambas as variáveis estão computadas em equivalentes-homem. 
O tamanho da família não está associado ao tamanho do estabelecimento rural, ou seja, aos subsistemas. As menores e as maiores unidades produtivas indicam tamanhos semelhantes de familia aos estratos intermediários, principalmente os subsistemas três e quatro correspondem a famílias formadas por casais mais novos com filhos pequenos, sem idade de trabalho e, por isso, aparecem como "menores" do que as outras.

TABELA 9 - MÉDIA DE EQUIVALENTES-HOMEM DA "FAMILIA-RURAL" DA FORÇA DE TRABALHO FAMILIAR TOTAL E POR HECTARE, POR SUBSISTEMA, EREXIM, RS - 1984/1985.

\begin{tabular}{|c|c|c|c|c|c|c|c|c|}
\hline \multirow{2}{*}{ Categorias } & \multicolumn{8}{|c|}{ Subsistemas (SBs) } \\
\hline & $\mathrm{SB}_{1}$ & $\mathrm{AB}_{2}$ & $\mathrm{SB}_{3}$ & $\mathrm{SB}_{4}$ & $\mathrm{SB}_{5}$ & $\mathrm{SB}_{6}$ & $\mathrm{SB}_{7}$ & $\mathrm{SB}_{\mathbf{8}}$ \\
\hline $\begin{array}{l}\text { Famflia } \\
\text { Força de Trabalho }\end{array}$ & 4,27 & 5,17 & 2,64 & 3,08 & 3,80 & 3,43 & 4,40 & 4,87 \\
\hline $\begin{array}{l}\text { Total } \\
\text { Força de Trabalho }\end{array}$ & 1,03 & 2,23 & 2,04 & 2,67 & 3,80 & 2,52 & 4,40 & 3,74 \\
\hline $\mathrm{H} / \mathrm{Ha}$ & 0,13 & 0,27 & 0,11 & 0,13 & 0,12 & 0,07 & 0,10 & 0,08 \\
\hline
\end{tabular}

FONTE: Dados de Pesquisa.

Observando-se a força de trabalho, que expressa a disponibilidade efetiva de mão-de-obra, percebe-se uma relação direta entre esta variável e o tamanho dos estabelecimentos. Nos primeiros estratos de tamanho, a força de trabalho, ou nivel de permanência da mão-deobra, é pequena se comparada com a dos últimos estratos. Existe, no caso, um ajustamento da mão-de-obra efetiva ás possibilidades de ocupação, ou seja, a escala de atividades. $O$ excesso de pessoas nas familias, nos pequenos estabelecimentos, em relação às opções de emprego, induz um processo migratório para outras áreas rurais ou urbanas.

O grau efetivo de ocupação da mão-de-obra disponível varia ao longo do ano, e as épocas em que a subocupação é maior tem a ver com os conjuntos de atividades praticadas. Comparando com um emprego integral, estimado em 9 horas-dia, durante 23 dias por mês, ou seja, 207 horas mensais, a taxa de subocupação é relativamente alta, como indicado na tabela seguinte. 
TABELA 10 - HORAS POR DIA DE OCUPAÇÃo PRODUTIVA DA MĀODE-OBRA FAMILIAR, AO LONGO DO ANO, POR SUBSISTEMA, EREXIM, RS - 1984/1985.

\begin{tabular}{lcccccccc} 
& \multicolumn{7}{c}{ Horas de Ocupação/dia da ḾO Disponivel } \\
\cline { 2 - 8 } & $\mathrm{SB}_{1}$ & $\mathrm{SB}_{2}$ & $\mathrm{SB}_{3}$ & $\mathrm{SB}_{4}$ & $\mathrm{SB}_{5}$ & $\mathrm{SB}_{6}$ & $\mathrm{SB}_{7}$ & $\mathrm{SB}_{8}$ \\
\hline Junho-julho & 4,6 & 6,4 & 8,3 & 2,9 & 4,9 & 2,5 & 2,1 & 1,9 \\
Agosto-Setembro & 7,4 & 6,8 & 7,0 & 4,2 & 4,9 & 5,1 & 3,2 & 3,2 \\
Outubro-Novembro & 8,3 & 6,3 & 7,4 & 4,4 & 4,4 & 5,3 & 3,7 & 4,3 \\
Dezembro-Janeiro & 6,0 & 2,9 & 4,4 & 6,0 & 4,7 & 6,6 & 4,1 & 5,0 \\
Fevereiro-Março & 4,6 & 1,1 & 2,1 & 4,4 & 2,6 & 4,2 & 2,4 & 3,3 \\
Abril-Maio & 7,4 & 3,9 & 5,3 & 7,5 & 6,1 & 8,2 & 4,6 & 6,1 \\
\hline
\end{tabular}

FONTE: Dados de Pesquisa.

A ocupação efetiva da mão-de-obra permanece abaixo dos limites potenciais estabelecidos, em todos os subsistemas e em cada um dos períodos. Em termos médios, portanto, há mão-de-obra em excesso na pequena produção de Erexim, apesar da evasão já computada.

Nos subsistemas sem plantio isolado da soja (SB1, SB2, SB3), a ocupação mais intensiva da mão-de-obra verifica-se de julho ou agosto até outubro ou novembro, periodo de colheita de trigo se cultivado, e preparação da terra, plantio e capinas de milho e plantio da soja em consorciação com o milho. Nesse perlodo, também são plantadas as culturas de subsistência. No caso de plantio isolado de milho e soja, principalmente quando esta se torna a cultura predominante (SB6, SB7 e SB8), a concentração do trabalho efetivo realiza-se em outubro e dezembro e depois, em abril e maio.

\subsection{Margens Brutas e renda do Capital de Exploração Fixo}

A margem bruta é computada pela diferença entre a receita total e os custos variáveis de produção.

A receita total corresponde ao valor bruto da produção e foi calculada como vendas mais consumo interno, mais variações de inventário, subtraidas compras de produtos ou insumos, feitas durante o período.

Os custos variáveis incluem a imputação de salário da mão-deobra, gastos com animais, custos de máquinas e equipamentos, insumos, adubos e medicamentos. 
Para a mão-de-obra, computou-se 13 salários-mínimos-ano, para as tarefas não especializadas, e um acréscimo de $30 \%$ sobre o saláriomínimo para tarefas especializadas.

O custo de máquinas inclui, além dos direitos e de depreciação, um juro de $6 \%$ aó ano sobre o capital.

Para rebanhos, construções, benfeitorias e capital fundiário, não estão imputados, nos custos, juros sobre o capital.

As margens brutas, computadas para cada subsistema, estão na tabela a seguir.

\section{TABELÁ11 - ORIGEM E MONTANTE DAS MARGENS BRUTAS, TOTAL E POR HECTARE, POR SUBSISTEMA DE PRODUÇÃo, EREXIM, RS - 1984/1985.}

\begin{tabular}{lccrr}
\hline & \multicolumn{2}{c}{ Origem $(\%)$} & \multicolumn{2}{c}{ Valor (Cz\$) } \\
Subsistemas & Culturas & Criações & \multicolumn{1}{c}{ Total } & \multicolumn{1}{c}{ Por Hectare } \\
\hline SB1 & 67,4 & 32,6 & $8.824,40$ & $1.080,10$ \\
SB2 & 75,5 & 24,6 & $17.275,69$ & $2.081,41$ \\
SB3 & 88,2 & 11,8 & $21.683,89$ & $1.178,47$ \\
SB4 & 70,9 & 29,1 & $22.544,39$ & $1.058,42$ \\
SB5 & 78,4 & 21,6 & $34,022,23$ & $1.088,71$ \\
SB6 & 84,9 & 15,1 & $28.044,25$ & 831,93 \\
SB7 & 81,2 & 18,8 & $47.707,89$ & $1.072,08$ \\
SB8 & 83,8 & 16,2 & $41.582,06$ & 929,83 \\
\hline
\end{tabular}

FONTE: Dados de Pesquisa.

As margens brutas variam de $67 \%$ a $88 \%$ entre os sistemas de produtos de lavouras e de $12 \%$ a $32 \%$ de receitas derivadas de produções de animais. Para a amostra inteira, a participação de lavouras é de $78,8 \%$ e, de produção animal, de $21,2 \%$.

Os acréscimos da renda bruta total são, aproximadamente, proporcionais aos aumentos das áreas dos estabelecimentos. Esta quase proporcionalidade está demonstrada nas margens por hectare, que são relativamente estáveis, com exceção dos subsistemas dois (SB2) e seis (SB6).

No cálculo da margem bruta por atividade, constatou-se que no SB1 a cultura de maior contribuição é a mandioca e a criação mais 
importante é a de suínos; nos subsistemas dois, três e quatro (SB2, SB3 e SB4), a atividade consorciada de milho e soja gera a maior parcela da margem bruta. Nos demais sistemas, a soja constitui a maior fonte de margem, seguida por milho, mandioca è criação de stínos (GOLLO, 1987 P. 78).

\section{CONCLUSÕES}

Os resultados obtidos neste trabalho indicam que a pequena produção do município de estudo apresenta um tamanho médio de 26,42 hectares. Desta área, em média, $49,9 \%$ é cultivada com culturas anuais, e as mais representativas são o milho e a soja em plantio isolado ou consorciado e o trigo. O pequeno produtor dedica-se, também, ao plantio do feijão, arroz, mandioca e batata-inglesa.

Da produção total de milho, $81 \%$ destina-se ao consumo interno da propriedade, enquanto $99,6 \%$ da produção de soja e $84,2 \%$ da produção de trigo e $72,4 \%$ da produção de feijão destinam-se à comercialização. $O$ arroz, a mandioca e a batata-inglesa são produzidos visando ao abastecimento interno.

Em termos de subsistemas, constatou-se que a área média é de aproximadamente 26,29 hectares. 0 milho (isolado ou em consórcio com a soja), a soja, o trigo, o feijão e a mandioca são as culturas mais representativas. À medida que o tamanho da propriedade aumenta, há uma reduçāo na área relativa de milho e uma elevação na área de soja. Nas menores propriedades, o consórcio milho $x$ soja é praticado mais intensamente. As atividades de arroz, mandioca e batata-inglesa têm características de subsistência. $\mathrm{Na}$ exploração animal, destacamse a bovinocultura de leite, os suínos e as aves coloniais.

O número médio de pessoas da família é de 3,96 equivalenteshomem e a mão-de-obra é mais intensamente ocupada nos meses de abril, maio, outubro e novembro. As épocas em que a ocupação da mão-de-obra é maior têm a ver com os conjuntos de atividades praticadas. A ocupação efetiva da mão-de-obra é menor que o limite potencial, havendo, portanto, excesso de mão-de-obra na pequena produçāo de Erexim.

A margem bruta por hectare é, em média, de $\mathrm{Cz} \$ 1.165,19$, representando 1,45 salários-mínimos mensais. As margens brutas formam-se de aproximadamente $78,8 \%$ dos produtos de lavouras e $21,2 \%$ da produção. 
A partir destes resultados, conclui-se que o aumento no nível produtivo das atividades de mandioca, feijão e batata-inglesa provocam uma elevação na margem bruta do pequeno produtor. No entanto, us aumentos na produção destas atividades gerarão produtos excedentes em nivel de propriedade que deverão ser transferidos ao mercado. Verificou-se que, no caso da batata-inglesa, parte do aumento da produção seria consumida pela demanda local, tendo em vista que, atualmente, o mercado urbano do município é quase que totalmente abastecido pela oferta advinda dos estados do Paraná e São Paulo. Já o incremento na produção da mandioca criaria dificuldades no mercado, pela ausência de indústria para adquirir e transformar os produtos excedentes. Sugerem-se estudos sobre a viabilidade econômica de implantar-se farinheiras, fecularias e/ou destilarias no município, com o objetivo de absorver o excedente de oferta de produto e elevar o nivel de renda e emprego nos setores rurais e urbanos.

A soja deve ser plantada em consorciação com o milho nas propriedades onde o fator terra é mais restritivo e que utilizam tração animal. À medida que o tamanho da propriedade aumenta, é recomendado o plantio isolado além da consorciação milho $x$ soja, utilizando tração mecânica.

As conbinações de atividades praticadas atualmente no município nāo possibilitam uma ocupação total da mão-de-obra disponivel, principalmente nos meses de janeiro, fevereiro, março e dezembro. Sugerem-se estudos no sentido de determinar a introdução de novas atividades que venham a ocupar a mão-de-obra disponivel nestes períodos, elevando o nivel de renda. Entre estas atividades a serem restadas, poderiam estar o alho, a cebola, frutiferas, etc.

\section{REFERÊNCIAS BIBLIOGRÁFICAS}

CASSOL, Ernesto. Formação Histórica da Grande Erechim. Propostas Para Linhas Essenciais Para seu Estudo. Revista Perspectiva. Erechim, FAPES, 2(6):9-17, jan. 1979.

CENSO AGROPECUÁRIO DO RIO GRANDE DO SUL 1970. Fundação Instituto Brasileiro de Geografia e Estatística - IBGE. Rio de Janeiro, IBGE, 1974, v. 3, t.XXI. 
CENSO AGROPECUARIO DO RIO GRANDE DO SUL 1980. Fundação Instituto Brasileiro de Geografia e Estatística - IBGE. Rio de Janeiro, IBGE, 1983, v. 2, t. III.

CENSO DEMOGRÁFICO DO RIO GRANDE DO SUL 1980. Fundaçāo Instituto Brasileiro de Geografia e Estatística - IBGE. Rio de Janeiro, IBGE, 1981, v. 1, t. IV.

GOLLO, Silvana S. A Pequena Produção Agrícola: Alocação de Recursos e Combinação de Atividades em Pequenas Propriedades no Municipio de Erechim - RS. Porto Alegre, IEPE, 1987, 180 P. (Dissert. Mestrado Econ. Rural).

KAGEYAMA, Angela \& SILVA, José G. da. Política Agnícola e Produção Familiar. In: CONGRESSO BRASILEIRO DE ECONOMIA RURAL, 24. Lavras, MG, 28 de jul. a 1 de ago. 1986. Anais... Brasília, SOBER, 1986, v. 1, p. 199-221.

KONZEN, Otto G. A Pequena Propriedade Rural em Santa Catarina. Análise Econômica. Porto Alegre, Faculdade de Ciências Econômicas/UFRGS, 4(7):39-62, nov. 1986.

KONZEN, Otto G. \& RICHTER, Humberto V. Estrutura da Produção e Renda Agrícola em Diferentes Estabelecimentos Rurais no Brasil. Revista de Economia Rural. Brasilia, Sober, 20(2):237-67, abr.jun., 1982.

PIRAN, Nedio. A Pequena Propriedade Rural em Erechim: um Estudo de Caso. Rio Claro, UNESP, 1982, 161 p. (Dissert. Mestr. Geografia).

SILVA, José G. da. Tecnologia e Campesinato: o Caso Brasileiro. In: ENCONTRO NACIONAL DE GEOGRAFIA AGRÁRIA, 5. Santa Maria, 1984, p. 44-83.

\section{ABSTRACT}

Most rural production units in the municipality of Erechim (RS, Brazil) are small farms. This municipality is our study area.

The focus of the study is on production organization, employment, technology and farm family income of four small farm systems and eight subsystems of those farms. 
Corn, soybeans and wheat are the main crops and the basic source of production value. But, dairy cattle, hogs and chicken are also generally produced by the farmers.

A comparison of "family size" to "family labor force on the farm" and "farm size" indicated a closer relation of the "family labor force on the farm" with the "farm size" than between the "family size" and "farm size", indicating employment oportunity as a condition for the farmers to remain on the farm. 